\title{
Sexual Perversion Leads to Laparotomy
}

\author{
Shahameen Aqeel ${ }^{1}$ and Areeba Aqeel ${ }^{2 *}$ \\ 'Department of Physiology, University of Karachi, Karachi, Pakistan \\ ${ }^{2}$ Department of General Surgery, Abbasi Shaheed Hospital, Karachi, Pakistan
}

\begin{abstract}
Insertion of objects/stuff in bodily orifice is not unusual. There are many causes of penetration of bowel with different objects inserted via anus as to achieve sexual pleasure, to satisfy lust, self-injury, malingering and human trafficking is known for centuries. There are different household products used by the people to satisfy their lust/sexual desire but the objects/stuff used for this purpose mainly cylindrical and a type of soft texture. These objects are known for potential damage to gastrointestinal tract but it also affects other parts of the body and may create different inner complications, which needs to be evaluated and managed accordingly. Sometimes, management only requires local intervention, but if complications are build up like perforation develop needs laparotomy, broad-spectrum antibiotic therapy, repair of perforation with or without colostomy.
\end{abstract}

Keywords: Perversion, foreign body, laparotomy, rectosigmoid colon, peritonitis, perforation.

\section{INTRODUCTION}

Sexual perversion is a vast term used for an unnatural form of sex. Any sexual desire or practice other than heterosexual genital intercourse comes in sexual perversions. The following are some points to define sexual perversion [1]. The main concept of perversion was well defined in the nineteenth century, moreover, perversion was present before the eighteenth century but Krafft-Ebing in his book named Psychopathia Sexualis (published in 1886 in German), describes different types of perversions like sadism, masochism, fetishism, pederasty, bestiality, homosexuality, lesbian love, necrophilia, incest and so on. Havelock Ellis in his book Psychology of Sex (1897-1928), also explains auto-eroticism, Eonism (cross-dressing) and undinism (urinating and sex) [2]. According to Freud's as defined in his article that perversion is pathological sex, in which loss of shame, disgust, fear and pain with the characteristic feature of fixation to genitals. Perversion may result from previous trauma [2, 3]. Paraphilic disorders cause long-term harm to the person itself but for society also [3]. The most common form of perversion, nowadays experience in our society is Fetishism, in which sexual desire is accomplished by a loaded object or fetish. Fetish can be anything an object or a body part that causes sexual arousal [4]. In order to satisfy the foreign body (FB)' lust, it was started in the Sixteenth century and is more commonly seen in Europe as compared to Asia [5]. In most cases, different household objects like fruits and vegetables are used by people in order to satisfy their sexual desire and most commonly inserted in the anus.

The cases of the rectal foreign body are increasing day by day mainly in the urban population and it has been noted through the survey that the males of middle age

*Corresponding author: Areeba Aqeel, Department of General Surgery, Abbasi Shaheed Hospital, Karachi, Pakistan,

Email: areebaaqeel93@gmail.com

Received: February 15, 2021; Revised: May 28, 2021; Accepted: June 03, 2021 DOI: https://doi.org/10.37184/lnjpc.2707-3521.3.7 are more commonly affected by this act. The object can be used of any size $[6,7]$. There are two types of FB insertion either voluntary or involuntary. Voluntary FB is mostly used for sexual perversion but involuntary FB is mostly found in cases of rape, sexual assault and smuggling of drugs in the form of packets [8]. Patients mainly come to the emergency room with complaints of vague abdominal pain, vomiting or constipation. The main problem to diagnose a foreign body is the late presentation, which is due to guilt and feeling of shame so they are reluctant to seek any medical treatment, which results in further delay of their management and treatment [9]. In most cases, diagnosis via per rectal examination, rigid proctoscopy and X-ray abdomen and pelvis are usually helpful in identifying nature, extent, number, size and exact location of foreign body. Removal can be done mostly via tans anal but if the FB is more than $10 \mathrm{~cm}$ as well as fragile and sharp then it is usually removed by laparotomy [10, 11]. Eftatia et al. classified foreign bodies in the rectum as high and low lying. Those foreign bodies, which are higher in relation to the rectosigmoid colon are high and need laparotomy for their removal and those which are low lying to rectosigmoid can be removed through trans anal [12]. Due to late diagnosis and management, various complications may be developed i.e perforation, peritonitis, sepsis and death [13].

\section{DISCUSSION}

A colorectal foreign body is not much uncommon nowadays. It can be presented at any age and any ethnic group but commonly in East Europe than Asia [14]. It was firstly started in Sixteenth-century but published in 1919 [15].

According to the study conducted in 2019 , by Shahid Mirani and his fellows, describe that $35 \%$ of the injuries were voluntary while $65 \%$ were involuntary. Males were predominant mainly of the 3rd and 4th decade of life and also describe that patients with intestinal obstruction and 
peritonitis need exploratory laparotomy [8]. Most common reason for the insertion of a foreign body to fulfill sexual desire is approximately more than half of the cases, but other cases are for the self-treatment of constipation, hemorrhoids, psychiatric patients and other injuries. The main objects used for grafting are household products with a smooth texture and are cylindrical $[16,17]$. Patients, who are presented to the emergency room with delay due to guilt or unsuccessful self attempts [18] result in further complications like perforation, contamination with feces, sepsis and hydrodynamic instability which further delay in management and may need diversion procedures [19].

Different methods are used for diagnosis first history and examination. Low lying foreign body can easily be palpable via DRE and can be removed by transanal manure but in case of high lying FB or FB with complications like perforation or peritonitis, laparotomy is necessary to save the patient life [20]. Usually, plain X.ray for the abdomen is used but to know the exact location of the foreign body, CT scan plain or contrast can be used but if the nature of FB is unknown then Magnetic Field Resonance (MRI) is strictly prohibited in the above scenario [15]. There are many techniques used to remove the rectal FB. The minimally invasive process should be used first digital or bimanual process attempted if it fails then endoscope can be used but in case of impacted FB then laparotomy is warranted $[11,21]$.

\section{CONCLUSION}

To conclude foreign body in the rectum is not much common nowadays. From different reports, it is transpired that more than $50 \%$ of cases are to fulfill their sexual desire [22]. Due to this sexual behavior or perversion, FB inserted in the rectum which does not only damage mucosa but also results in lacerations, tear to the anal sphincter and may result in peritonitis and perforations. Higher impacted FB requires laparotomy $[23,24]$.

\section{CONFLICT OF INTEREST}

The authors declare no conflict of interest.

\section{ACKNOWLEDGEMENTS}

Declared none.

\section{REFERENCES}

1. Begon J. Sexual perversion: a liberal account. J Soc Philos 2019; 50(3): 341-62.

2. Peakman J. Sexual perversion in history: an introduction. In: Peakman J, Eds. Sexual Perversions. London: Palgrave Macmillan 2009: pp. 1670-890.

3. Airaksinen T. Tricky sexual differences: what is perversion? In: Vagaries of Desire: A Collection of Philosophical Essays. Leiden: Brill Rodopi 2019: pp. 202-21.

4. Høgh-Olesen H. Aesthetics and fetishism: key stimuli and power objects. Evolution Stud Imagin Cult 2018; 2(2): 21-32.
5. Khan HS, Ayyaz M. Foriegn body in rectum: an unusual case. J Ayub Med Coll Abbottabad 2016; 28(2): 413-4.

6. Talukdar MMI, Akter Q, Al Mamun MA, Ansary AMAA. Rectal foreign body in a 30 year old male-a case report. J Shaheed Suhrawardy Med Coll 2017; 9(1): 35-7.

7. Gajjar RA, Gupta PB. Foreign body in the rectum: a challenge for the emergency physician. J Family Med Prim Care 2016; 5(2): 495-7.

8. Mirani S, Awan A, Mirani AS. Rectal foreign bodies: a case series from Pakistan. Rawal Med J 2019; 44(1): 94-8.

9. Mathi M, Arun A, Nelson R, Andre Das UG. Anal Eroticism with plastic bottle ways of management: a case report. Glob J Medical Clin Case Rep 2017; 4(3): 065-8.

10. Soujanya M, Kulkarni SB, Kruthi SR, Santosh MP, Prakash OG. Unusual foreign body in rectum: a surgical curiosity. Int Surg J 2021; 8(2): 719-21.

11. Narjis $Y$, Rabbani $K$, Hakkou K, Aboulhassan $T$, Louzi $A$, Benelkhayat $\mathrm{R}$, et al. Foreign body of the rectum: an unusual case. J Emerg Trauma Shock 2010; 3(3): 306.

12. Cheereth RG, Ninan GA. Rectal foreign body: a case report. Int Surg J 2017; 4(3): 1119-22.

13. Gupta R, Mala TA, Gupta A, Gupta AK, Paul R. Acute appendicitis resulting from rectosigmoid foreign body. Formos J Surg 2014; 47(5): 204-6.

14. Coskun A, Erkan N, Yakan S, Yıldirim M, Cengiz F. Management of rectal foreign bodies. World J Emerg Surg 2013; 8(1): 1-5.

15. Moniruddin A, Faisal MFH, Chowdhury S, Hasan T, Rafique R, Banerjee G, et al. Sigmoid resection and primary anastomosis without any diversion or exteriorization for impacted foreign body in sigmoid Colon. KYAMC J 2020; 10(4): 214-8.

16. Sangar P, Henry G, Sood S. Foreign bodies in the rectum: report of a case series and review of the literature. Sri Lanka J Surg 2013; 31(2): 27-30.

17. Ramadoss M. A rare case of foreign body rectum. Univ J Surg Surg Spec 2017; 3(3): 20-4.

18. Irpatgire R, Sarda V, Kale D. Rectal foreign body: case report and review of literature. Int Surg J 2016; 3(4): 2334-6.

19. Patel MS, Padghane $C$, Kulkarni VM. Perianal and rectal injury due to unusual foreign body-bell. Int Surg J 2018 5(3): 1124-6.

20. Lazzari V, Siboni S, Asti E, Bonavina L. Transanal removal of a broken drinking glass self-inserted and retained in the rectum. BMJ Case Rep 2017; 2017: bcr-2017220268.

21. Wani NA, Kosar TL, Ahmad A, Yusuf M. Foreign body of the rectum: an unusual case. AJR Am J Roentgenol 2001; 177:1137-40.

22. Jung E-J, Ryu C-G, Kim G, Hwang D-Y. Impaction of a foreign body in the rectum by improper use of a (electronic) massager: a case report. J Korean Soc Coloproctol 2010; 26(4): 298-301.

23. Unruh BT, Nejad SH, Stern TW, Stern TA. Insertion of foreign bodies (polyembolokoilamania): underpinnings and management strategies. Prim Care Companion CNS Disord 2012; 14(1): PCC.11f01192.

24. Lee JH, Kang SB, Ha DC, Kwon KH, Lee SW, Kim YS, et al. A case of a colon perforation due to a soft rectal foreign body. Korean J Gastrointest Endosc 2011; 43(1): 52-5. 